
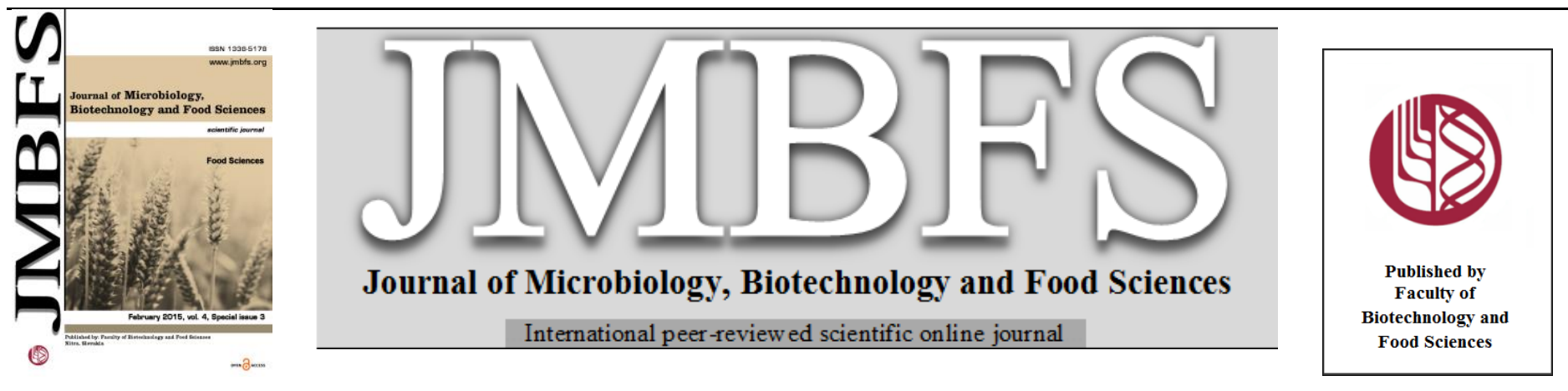

\title{
ANTIOXIDANT ACTIVITY IN NAKED AND HULLED OAT (AVENA SATIVA L.) VARIETIES
}

\author{
Daniela Chmelová*l, Miroslav Ondrejovič ${ }^{1}$, Michaela Havrlentovál ${ }^{1}$, Peter Hozlár ${ }^{2}$ \\ Address(es): RNDr. Daniela Chmelová, PhD., \\ ${ }^{1}$ University of Ss. Cyril and Methodius, Faculty of Natural Sciences, Department of Biotechnology, Nám. J. Herdu 2, 91701 Trnava, Slovak Republic. \\ ${ }^{2}$ Plant Production Research Center, Bratislavska cesta 122, Pieštany, SK-921 68, Slovak Republic.
}

*Corresponding author:daniela.chmelova@gmail.com

doi: 10.15414/jmbfs.2015.4.special3.63-65

\section{ARTICLE INFO}

Received 4. 12. 2014

Revised 15. 12. 2014

Accepted 16. 12. 2014

Published 2. 2. 2015

Regular article

open 2 access

\section{INTRODUCTION}

Many epidemiological studies have indicated that consumption of whole grain and whole-grain products is related to reduce incidences of chronic diseases (Liu et al., 2000; Mellen et al., 2008; Haas et al., 2009). Whole-grain and wholegrain products contain a number of polyphenols (benzoic and cinnamic acids, anthocyanidins, quinones, flavonols, chalcones, flavanones and amino phenols) with antioxidant activities. Antioxidant components of cereal grains are believed to be the major factors to their health benefits (Serpen et al., 2008) and may contribute to the protective effects against cardiovascular diseases and cancer. Oat (Avena sativa L.) is used as healthy foods due a significant content of antioxidant substances (Chen et al., 2007). Oats contain large amount phenolic compounds (ferulic, caffeic, $p$-hydroxybenzoic, $p$-hydroxyphenylacetic, vanillic, protocatechuic, syringic, $p$-coumaric and sinapic acids), tocols, phytic acid, flavonoids, sterols, avenanthramides and $\beta$-glucans (Sosulski et al., 1982; Chen et al., 2007). These polyphenols are unevenly distributed within the kernel or hulls (Emmons et al., 1999; Emmons and Peterson, 1999) and their amounts depend on the varieties, environmental conditions and treatment type (Adom et al., 2005). On the base of their concentration, colors of each grain parts (endosperm, aleuronic layer, pericarp, hulls) varied from white through yellow, grey, red to black.

Different methods to release free polyphenols with antioxidant activities have been developed. Free polyphenols are easy extracted to various solvents such as methanol, ethanol, acetone, diethyl ether etc. Solubility of polyphenols is affected by polarity of solvent used. Because the free phenolic acids (benzoic or cinnamic acids) with antioxidant activities are present in plant material in the form of their salts, they are better extracted by mixtures of alcohol and water or acetone and water (Stalikas, 2007). Parameters affected extraction efficiency are selection of solvent(s), extraction time and temperature and solid-liquid ratio.

The objectives of the present work were to evaluate the effect of different extraction conditions (solvent, methanol concentration, size particles, solid-liquid ratio (w/v) and extraction time) in naked and hulled (yellow, black and white) oat varieties from Slovak Republic.

\section{MATERIAL AND METHODS}

Chemicals

All chemicals were analytical grade and were purchased from Merck (GE) and Sigma Aldrich (USA).

\section{Plant material}

It was used samples of oat (Avena sativa L.), especially naked (Tatran), white (Fredy), yellow (Atego) and black (Paddock) hulled oats. Oat varieties were grown in the year 2012 on a field at Plant Production Research Institute in Piešt'any (Slovak Republic).

\section{Extraction procedure}

The varied conditions in logical relation to TEAC were as follows: solvent (water, methanol, isopropanol, chloroform and $n$-hexane), methanol concentration $(0,25,50,75$ and $100 \%$; v/v), size particles $(<0.1 \mathrm{~mm} ; 0.1-1.0$ $\mathrm{mm}$ and $>0.1 \mathrm{~mm})$ and solid-methanol ratio $(1: 10 ; 1: 25 ; 1: 50 ; 1: 75 ; 1: 100 ; 1: 200$ 1:300 and 1:500; w/v) and extraction time $(0-420 \mathrm{~min})$. The effect of solvents, methanol concentration and size particles was evaluated at $22{ }^{\circ} \mathrm{C}$ during 24 hours at solid-liquid ratio of 1:100 (w/v) with size particles $<0.1 \mathrm{~mm}$. Selected solidmethanol ratio were evaluated at $22^{\circ} \mathrm{C}$ during 24 hours with size particles $<0.1$ $\mathrm{mm}$. Kinetic of antioxidant extraction was measured during 420 minutes at $22{ }^{\circ} \mathrm{C}$ and solid-liquid ratio 1:200 (w/v) with size particles $<0.1 \mathrm{~mm}$. After extraction time, the solution was centrifuged for 10 minutes at 4,000 RPM. Solvent was evaporated and the residue was dissolved in methanol $(0.5 \mathrm{ml})$ and extract was used for analysis.

\section{Antioxidant activity}

Antioxidant activity of samples was measured using the 2,2-diphenyl-1picrylhydrazyl (DPPH) (Yen and Chen, 1995). The extracts $(25 \mu \mathrm{l})$ were mixed with $100 \mu \mathrm{l}$ of DPPH solution (0.012 $\mathrm{g} \mathrm{DPPH}$ in $100 \mathrm{ml}$ methanol). After 10 minutes incubation at laboratory temperature, absorbance of the reaction mixtures was determined using the BioTek Microplate Reader (ELx800, USA) at $540 \mathrm{~nm}$. Trolox (6-hydroxy-2,5,7,8-tetramethylchroman-2-carboxylic acid) was used as the standard. The results of antioxidant activity were expressed in TEAC (trolox equivalent antioxidant capacity) calculated as $\mu \mathrm{g}$ of trolox to $\mathrm{g}$ of dry plant material.

\section{Statistical analysis}

The results represent means $\pm \mathrm{SD}$ from three measurements. Statistical significance was set at $\mathrm{p}<0.05$. 


\section{RESULTS AND DISCUSSION}

The present study provides analysis of the antioxidant activities of oat varieties from Slovak Republic. Oat varieties were naked (Tatran), and white (Fredy), yellow (Atego) and black (Paddock) hulled oats. All samples originated form one growing season and were grown under the same agronomic conditions. Oats are a rich source of many antioxidant compounds such as polyphenols, tocols and avenanthramides which can be determined by DPPH method (Chen et al., 2007) This method is cheap, cost effective, easily interpreted and useful for screening and comparing large numbers of samples (Ryan et al., 2011).

Whereas the antioxidants present in oats belong to different chemical classes with various physicochemical properties, we tested the effect of polarity of solvent to the extraction efficiency of obtaining antioxidants. In the literature, for antioxidant extraction, various extraction solvents such as acetone, methanol, ethanol or their water solutions were used (Cai et al., 2011; Ryan et al., 2011; Rakic et al., 2014). For antioxidant extraction from oat varieties in this experiment, solvents such as water, methanol, isopropanol, chloroform and $n$ hexane were used.

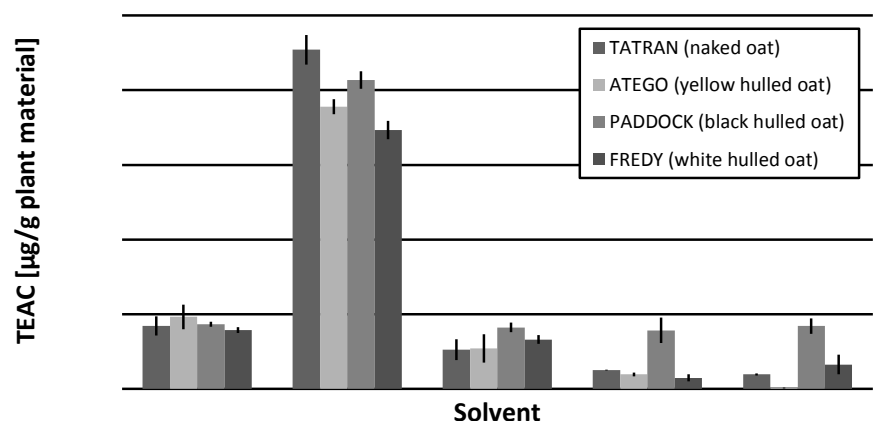

Figure 1 The effect of different solvents on antioxidant extraction from oat varieties

The antioxidant activity of the samples ranged of 0.6 to $227.0 \mu \mathrm{g} / \mathrm{g}$ plan materials and varied within the varieties. As shown in Fig. 1, methanol extracts had the strongest antioxidant activity, followed by water extracts. The antioxidant activities of isopropanol and chloroform and $n$-hexane extracts were the weakest These results indicate that main of antioxidants of tested oat varieties is polar compounds (Cai et al., 2011).Compared with methanol extracts, antioxidant activities of water extracts was from 3.9 to 5.4-fold lower. There was greater variation in antioxidant activities present in different oat varieties. The highes antioxidant activities were measured in Tatran $(227.0 \mathrm{ug} / \mathrm{g}$ plant material), than Paddock (206.7 ug/g plant material), Atego (188.9 ug/g plant material) and the lowest antioxidant activities was observed in white hulled oat Fredy (173.3 ug/g plant material). Similarly, Brindzová et al. (2008) found that black hulled oats showed the highest antioxidant activity in DPPH test in compared with yellow hulled oats and naked oats.

Because water and methanol appeared to be the best extraction solvent for antioxidant compounds, the effect of water-methanol ratio was tested. A range from 0 to $100 \%(\mathrm{v} / \mathrm{v})$ of methanol concentration in extraction solvent has been used for investigation.

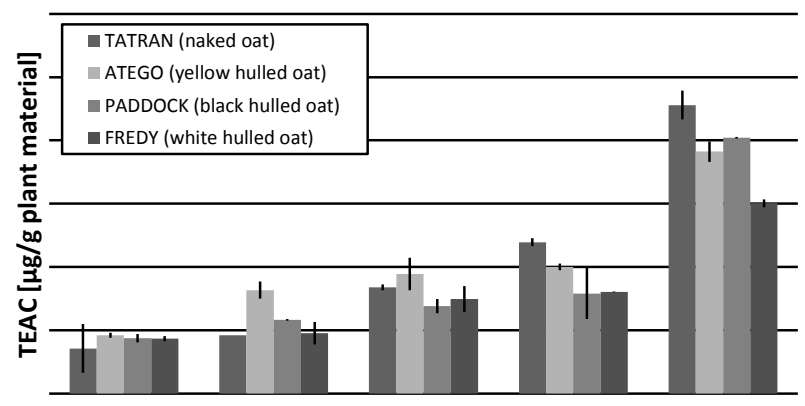

Methanol concentration

Figure 2 The effect of different methanol concentration in extraction solvent on antioxidant extraction from oat varieties

From Fig. 2, the amounts of the extracted antioxidants rapidly increased with increasing methanol concentration. The results indicate that antioxidan compounds were much more methanol soluble than in water or water solution of methanol. Antioxidant activity was increased in the order of Tatran, Paddock, Atego and Fredy with antioxidant activity 228.0, 202.6, 191.1 and $150.30 \mathrm{ug} / \mathrm{g}$ plant materials, respectively. Since the methanol extracts exhibited the highes antioxidant activities, it was further used as extraction solvent. Brindzova et al (2008) found that the highest antioxidant activities were observed in $65 \%(\mathrm{v} / \mathrm{v})$ ethanol extracts of black hulled oats in comparison to the grains with yellow hulls and naked oat varieties (approximately 3 -fold).

To improve the extraction efficiency, reduction of particle size may be used Particle size reduction can affect extraction efficiency due increasing specific surface of extraction particles and reducing of diffusion path. In our experiment oats were homogenized to variable particle size $(<0.1 \mathrm{~mm}, 0.1-1.0 \mathrm{~mm},>1.0$ $\mathrm{mm})$ and as control, non-homogenized oat materials was used for extraction. Results are shown in Fig. 3.

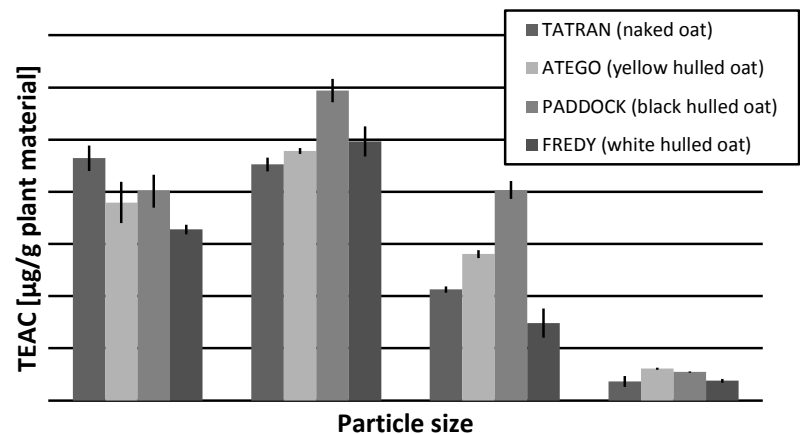

Figure 3 The effect of different particle sizes on antioxidant extraction from oat varieties

The importance of oat particle size on antioxidant activity was confirmed (Fig 3). Antioxidant activity was higher in fractions with particle sizes in range from 0.1 to $1.0 \mathrm{~mm}$, except naked oat Tatran, whose antioxidant activity remained comparable in fractions with particle sizes $<0.1 \mathrm{~mm}$ and $0.1-1.0 \mathrm{~mm}$ (232.2 and $226.1 \mathrm{ug} / \mathrm{g}$ plant material, respectively). In the case of particle sizes in range of $0.1-1.0 \mathrm{~mm}$, it was observed than hulled oats has the higher antioxidant activities than naked oat Tatran and the highest antioxidant activity was measured in black hulled oat Paddock (297.0 ug/g plant material). Fractions with particle sizes $>1.0 \mathrm{~mm}$ represent mainly hulls. Oat hulls contain significant quantities of soluble ferulic acid and several other phenolic acids (Emmons and Peterson, 1999). Significant amount of antioxidant compounds have been observed mainly in black hulled oat Paddock (201.6 ug/g plant material), but these fractions had lower levels of antioxidant activities than fractions with smaller particle sizes. Because the yields of antioxidants from various oat varieties were comparable and efficiency of extraction depends on solubility extracted compounds in extraction solvent, we tested different solid-liquid ratio (w/v). Antioxidan activities of oat methanol extracts prepared by various solid-liquid ratios are shown in Fig. 4.

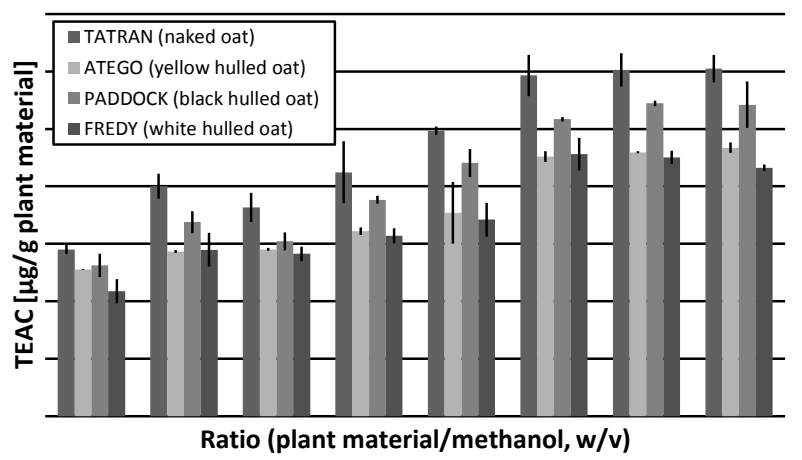

Figure 4 The effect of ratio between plant material and methanol on antioxidant activities in oat varieties

The amount of antioxidants was affected by the methanol concentration (Fig. 4). TEAC was increased with the increase of solid-liquid ratio until reaching a maximum at 1:200 (w/v) and then antioxidant activities were unchanged. Therefore, solid-liquid ratio of 1:200 (w/v) was selected as suitable ratio for kinetic of antioxidant extraction. In this experiment, the differences between oat varieties are better observable. The highest antioxidant activities were measured in extract of naked (Tatran) and black (Paddock) hulled oats, 302.6 and 272.2 $\mathrm{ug} / \mathrm{g}$ plant materials, respectively. Extraction time and temperature are also an important factor for antioxidant extraction from plant materials and it plays significant role in extraction efficiency and energy cost. Although extraction temperature may be benefit for bioactive compounds to release from plant material, but higher temperature may cause the degradation of some thermosensitive compounds (Ondrejovič et al., 2009). Therefore, the effect of 
extraction time on antioxidant activities in different oat varieties was investigated at the final step in series of preliminary experiments at laboratory temperature.

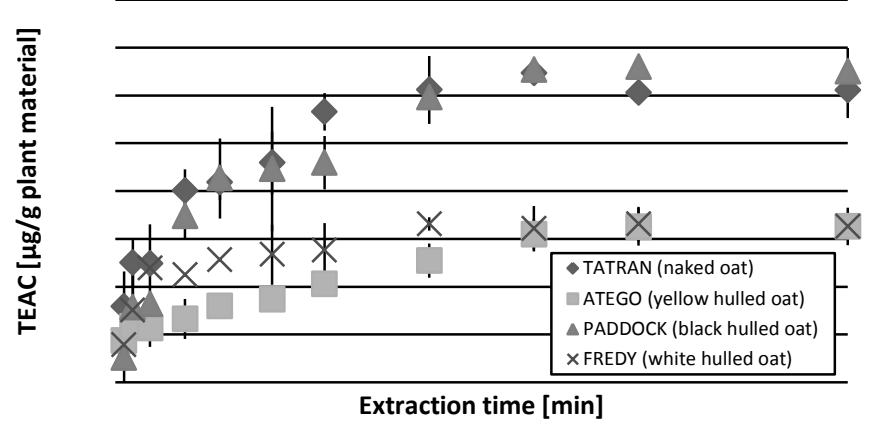

Figure 5 Kinetic of antioxidant extraction from oat varieties in ratio 1:200 (w/v) at $22{ }^{\circ} \mathrm{C}$

From the Fig. 5, antioxidant activities in extract of different oat varieties increased with the increase of extraction time from 0 to 240 minutes. Over 240 minutes, antioxidant activities aren't increased and remained fairly constant. Similarly, the highest antioxidant activities were measured in naked (Tatran) and black (Paddock) hulled oats (279.2 and $281.9 \mathrm{ug} / \mathrm{g}$ plant materials, respectively).

\section{CONCLUSION}

The aim of this study was the selection of suitable conditions for antioxidan extraction from naked (Tatran) and white (Fredy), yellow (Atego) and black (Paddock) hulled oats. We tested different solvents, methanol concentration, solid-liquid ratio and extraction time. The best conditions for antioxidan extraction for all oats were: methanol as extraction solvent, solid-liquid ratio 1:200 (w/v) during 240 minutes. The highest antioxidant activities were observed in naked (Tatran) oat and black (Paddock) hulled oat extracts.

Acknowledgments: This work was supported by APVV-VV-0758-11.

\section{REFERENCES}

ADOM, K.K., SORRELLS, M.E., LIU, R.H. 2005. Phytochemicals and antioxidant activity of milled fractions of different wheat varieties. Journal of Agricultural and Food Chemistry, 53(6), 2297-2306. http://dx.doi.org/10.1021/jf048456d

BRINDZOVÁ, L., ČERTÍK, M., RAPTA, P., ZALIBERA, M., MIKULAJOVÁ, A., TAKÁCSOVÁ, M. 2008. Antioxidant activity, $\beta$-glucan and lipid contents of oat varieties. Czech Journal of Food Sciences, 26(3), 163-173.

CAI, S., HUANG, C., JI, B., ZHOU, F., WISE, M.L., ZHANG, D., YANG, P. 2011. In vitro antioxidant activity and inhibitory effect, on oleic acid-induced hepatic steatosis, of fractions and subfractions from oat (Avena sativa L.) ethanol extract. Food Chemistry, 124(3), 900-905. http://dx.doi.org/ 10.1016/j.foodchem.2010.07.017

CHEN, C.Y., MILBURY, P.E., COLlinS, F.W., BluMBERG, J.B. 2007. Avenanthramides are bioavailable and have antioxidant activity in humans after acute consumption of an enriched mixture from oats. Journal of Nutrition, 137(6), 1375-1382.

EMMONS, C.L., PETERSON, D.M. 1999. Antioxidant activity and phenolic contents of oat groats and hulls. Cereal Chemistry, 76(6), 902-906. http://dx.doi.org/10.1094/CCHEM.1999.76.6.902

EMMONS, C.L., PETERSON, D.M., PAUL, G.L. 1999. Antioxidant capacity of oat (Avena sativa L.) extracts. 2. In vitro antioxidant activity and contents of phenolic and tocol antioxidants. Journal of Agricultural and Food Chemistry, 47(12), 4894-4898. http://dx.doi.org/ 10.1021/jf990530i

HAAS, P., MACHADO, M.J., ANTON, A.A., SILVA, A.S.S., DE FRANCISCO, A. 2009. Effectiveness of whole grain consumption in the prevention of colorectal cancer: meta-analysis of cohort studies. International Journal of Food Sciences and Nutrition, 60(6), 1-13. http://dx.doi.org/10.1080/09637480802183380

LIU, S., MANSON, J.E., STAMPFER, M.J., HU, F.B., GIOVANNUCCI, E., COLDITZ, G.A., HENNEKENS, C.H, WILLETT, W.C. 2000. A prospective study of whole grain intake and risk of type 2 diabetes mellitus in US women. American Journal of Public Health, 90(9), 1409-1415.

MELLEN, P.B., WALSH, T.F., HERRINGTON, D.M. 2008. Whole grain intake and cardiovascular disease: a meta-analysis. Nutrition, Metabolism \&
Cardiovascular

Diseases,

18(4),

$283-290$

http://dx.doi.org/10.1016/j.numecd.2006.12.008

ONDREJOVIČ, M., MALIAR, T., POLÍVKA, L., ŠILHÁR, Š. 2009. Polyfenoly jabĺk. Chemické Listy, 103, 394-400.

RAKIĆ, S., JANKOVIĆ, S., MARČETIĆ, M., ŽIVKOVIĆ, D., KUZEVSKI, J. 2014. The impact of storage on the primary and secondary metabolites, antioxidant activity and digestibility of oat grains (Avena sativa). Journal of Functional Foods, 7, 373-380. http://dx.doi.org/ 10.1016/j.jff.2014.01.022

RYAN, L., THONDRE, P.S., HENRY, C.J.K. 2011. Oat-based breakfast cereals are a rich source of polyphenols and high in antioxidant potential. Journal of Food Composition and Analysis, 24(7). 929-934. http://dx.doi.org/10.1016/j.jfca.2011.02.002

SERPEN, A., CAPUANO, E., FOGLIANO, V., GÖKMEN, V. 2007. A new procedure to measure the antioxidant activity of insoluble food components. Journal of Agricultural and Food Chemistry, 55(19), 7676-7681. http://dx.doi.org/10.1021/jf071291z

SOSULSKI, F., KRYGIER, K. AND HOGGE, L. 1982. Free, esterified and insoluble-bound phenolic acids. 3. Composition of phenolic acids in cereal and potato flours. Journal of Agricultural and Food Chemistry, 30(2), 337-340. http://dx.doi.org/10.1021/jf00110a030

STALIKAS, C.D. 2007. Extraction, separation, and detection methods for phenolic acids and flavonoids. Journal of Separation Science, 30(18), 3268-3295. http://dx.doi.org/10.1002/jssc.200700261

YEN, G.C., CHEN, H.Y. 1995. Antioxidant activity of various tea extracts in relation to their antimutagenicity. Journal of Agricultural and Food Chemistry, 43(1), 27-32. http://dx.doi.org/10.1021/jf00049a007 